\title{
SUDDEN INTERRUPTION OF GAS FLOW THROUGH A SCHRADER OXYGEN COUPLER UNIT
}

\author{
Douglas B. Craig and Jack Culligan
}

\begin{abstract}
The flow of oxygen to an anaesthetic gas machine suddenly and completely stopped during the course of a general anaesthetic. The cause of the failure was traced to a Schrader oxygen coupler check unit. During servicing, one component of the check unit had inadvertently been replaced by a similar but inappropriate component. Interruption of oxygen fow resulted from a loss of contact between two components of the check unit. This incident raises questions about the basic design and safety of Schrader coupler check units.
\end{abstract}

THE FLow of OXYGEN to an anaesthetic gas machine suddenly and completely stopped during the course of a general anaesthetic in which nitrous oxide and oxygen (5 LPM/3 LPM) were used. The anaesthetic machine was not equipped with an oxygen pressure failure protection device, nor an oxygen analyzer, and the absence of oxygen flow was detected only when the patient's general condition deteriorated. At this point, the reserve oxygen cylinder was opened, restoring oxygen flow, and the nitrous oxide was turned off. Although the patient suffered a short period of cardiovascular collapse, recovery was rapid, and there was no evidence of permanent sequlae.

Subsequent investigation revealed that the sudden interruption of oxygen flow had originated within a Schrader oxygen coupler check unit (Schrader \#4810*) (Figure 1). This unit was attached to the distal end of a three-metre oxygen hose (low pressure connecting assembly), the proximal end of which was securely attached to the oxygen pipeline terminal unit on the wall. The male component of the Schrader unit was appropriately secured within the female component. The problem was therefore not one of disconnection of the male to female linkage.

Disassembly of the malfunctioning oxygen coupler check unit revealed that one of the components, the deflator (Figures 1 and 2), was not of the appropriate type. As can be seen from Figure 1 , oxygen flow through the check unit will be

Douglas B. Craig, M.D., F.R.C.P.(C), Department of Anaesthesia, Health Sciences Centre and University of Manitoba. Jack Culligan, M.D., F.R.C.P.(C), Department of Anaesthesia, St. Boniface General Hospital and University of Manitoba.

Reprint Requests to: Douglas B. Craig, M.D., Department of Anaesthesia, Health Sciences Centre General, 700 William Avenue, Winnipeg. Manitoba, R3E 0Z3.

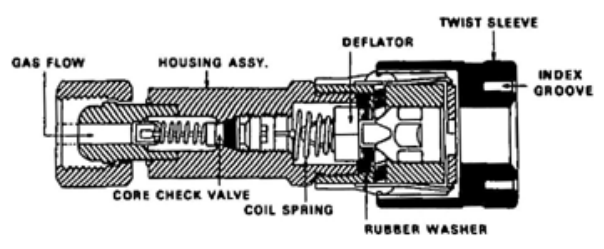

FIGURE I Female component of Schrader oxygen coupler check unit (Schrader Catalogue \#4810). Insertion of appropriate male component into twist sleeve depresses deflator which in turn depresses shaft of core check valve (similar to bicycle tire valve) "allowing oxygen to flow. ${ }^{3}$ Note shape of deflator (Schrader Catalogue \#2653A-3), with broad base in contact with small shaft of core check valve.

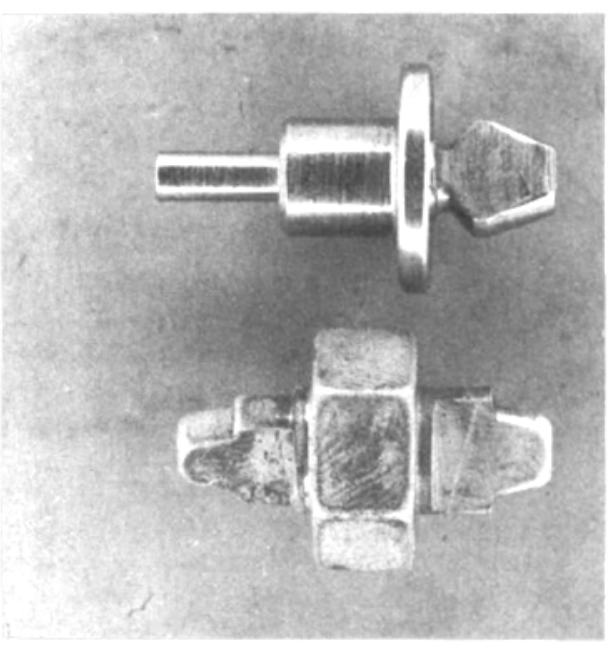

FIGURE 2 Top - Inappropriate deflator (Schrader \#4800A-13) which had been inserted in check unit during servicing. Note small pin on left side of deflator which would be in contact with small pin (see Figure 1) of core check valve. Bottom - Correct deflator (Schrader \#2653A-3) for Schrader oxygen coupler check unit (Schrader \#4810; Figure 1). 
initiated when the deflator is caused to depress the thin stem of the core check valve. The appropriate deflator (Schrader \#2653A-3*) (Figures 1 and 2) has a broad base, designed to make secure contact with the core check valve. The deflator present in our unit (Schrader \#4800A-13*) (Figure 2) had a thin stem designed to depress a ball check valve, not a core valve. It appears that the substituted deflator had depressed the stem of the core check valve at the start of the anaesthetic, but the small pin to small pin contact had subsequently slipped, causing the sudden interruption of oxygen flow. With careful insertion of the deflator, we were able to repeat the sequence of events, so that oxygen flow through the Schrader unit was present initially, but then abruptly terminated when the pin-to-pin contact was lost. Insertion of the appropriate deflator restored normal function.

\section{Discussion}

The cause of the life-threatening cessation of oxygen fiow clearly was the presence of the inappropriate deflator in the Schrader oxygen coupler check unit. Since this particular unit was at least ten years old, and had been serviced within the institution on a number of occasions the problem cannot be viewed as a manufacturing defect. Schrader oxygen check units of this type were first manufactured for medical use in $1948 . \dagger$ The specific problem described in this paper is the first which has been brought to the attention of the manufacturer. $\dagger$

How could this incident have been avoided? Potential solutions can be seen in two areas; one general, relating to the overall safety of oxygen delivery systems in anaesthesia, and one specific, relating to the actual mechanical problem which occurred in this case.

If an oxygen pressure failure protection device and alarm had been attached to the anaesthetic machine, the sudden loss of oxygen pressure would have caused the nitrous oxide flow to stop, and would have sounded an alarm. The Canadian Standards Association Z168.3-M 1978, preliminary standard for anaesthetic gas machines' includes a mandatory requirement for such a device. A province-wide program to implement this standard is now under way in Manitoba. Use of

*Catalogue numbers. Schrader Medical Gas Control Products, Armstrong Industries Inc., Northbrook, Illinois, U.S.A.

†Personal communication. Schrader Automative Products, Dickson, Tennessee. continuous oxygen monitoring within the patient circuit has long been advocated ${ }^{2}$ and is becoming increasingly common. The C.S.A. Standard Z168.3 encourages, but does not make mandatory, the use of continuous ox ygen monitoring. Of course, both these devices would only have made the lack of oxygen fiow apparent earlier. Intervention by way of re-establishing oxygen flow from the alternate source would still have been required.

Two features of the design of Schrader check units concern us. First is the possibility of accidental interchange of deflators, as happened in our unit. The Schrader catalogue lists four separate deflators, all with unique catalogue numbers, but without numerical or other designation on the deflators themselves. We feel consideration should be given to either a method of assuring non-interchangeability of deflators, or a system allowing direct identification of the four deflators, through labelling. We acknowledge that the chance of an inadvertent interchange of deflators would be reduced if personnel who service the check units were completely familiar with the various components. This is an ideal which is likely unattainable. Moreover, we do not think it is reasonable to have to rely on such a high degree of familiarity to compensate for a basic design feature which creates the possibility of error.

Our second concern about Schrader check units arises from the fact that some components of nitrous oxide and oxygen check units are interchangeable. For example, a nitrous oxide housing assembly (see Figure 1), appropriately attached to a nitrous oxide source, can be attached to an oxygen twist sleeve, the female component of the male to female linkage. Insertion of the male oxygen component, attached to an anaesthetic machine, into the female oxygen component attached to the compressed gas source, would then allow pure nitrous oxide to flow through the oxygen flowmeter of the anaesthetic machine. Although some of the current versions of the check unit components are labelled with the relevant chemical symbols, some are not, nor are older units. Even with identification through labelling, the identical thread of the nitrous oxide and oxygen housing assemblies and twist sleeves still allows inadvertent mixing of components. We do not think that this interchangeability of nitrous oxide and oxygen components is appropriate. Specific threads for each gas should be mandatory, as is the case for most other medical gas linkages. ${ }^{3}$

By publishing this report, we hope to make 
users of Schrader check units aware of the possibility of subtle but very important hazards associated with the design of the units. We have advised the Medical Devices Division, Health Protection Branch, Health and Welfare Canada of the problem.

\section{ACKNOWLEDGEMENTS}

The special assistance of the Medical Photography Department, Health Sciences Centre is gratefully acknowledged.

\section{REFERENCES}

1. Continuous flow inhalation anesthetic apparatus (anesthetic machines) for medical use. Z168.3-M 1978. Canadian Standards Association, Rexdale.

2. MAzzE, R.I. Therapeutic misadventures with oxygen delivery systems: the need for continuous inline oxygen monitors. Anes. Analg. 51: 787-792 (1972).

3. DoRsCh, J.A. \& DoRsCh, S.E. Understanding anesthesia equipment: construction, care and complications. Williams \& Wilkins, Baltimore (1975).

EDitorial Note: Canadian Standards Association Standard Z305.2-Low Pressure Connecting Assembly will be published early in 1980 .

\section{RÉSUMÉ}

Les auteurs rapportent l'arrèt soudain et total de l'écoulement de l'oxygène d'un appareil d'anesthésie au cours d'une anesthésie générale. La cause de cette panne se situait au niveau des raccords d'accouplement de type Schrader. Lors de l'entretien, une pièce du raccord avait été remplacée par inadvertence par une pièce similaire mais inappropriée. L'interruption de l'écoulement du gaz fut causé par la perte de contact entre les deux parties du raccord d'accouplement. Cet incident soulève des questions sur la conception et la sécurité des raccords de type Schrader. 